\title{
New possibilities of screening for mental disorders in cardiology practice
}

\author{
S. F.Zadvorev ${ }^{1}$, M. V. Dorofeikova ${ }^{2}$, N. N. Petrova ${ }^{3}$, A. A. Yakovlev ${ }^{1,3}$ \\ ${ }^{1}$ St. Petersburg Multidisciplinary Hospital No. 2, \\ 5, Uchebniy per., St. Petersburg, 194354, Russian Federation \\ 2 Sechenov Institute of Evolutionary Physiology and Biochemistry, Russian Academy of Sciences, \\ 44, pr. Toreza, St. Petersburg, 194223, Russian Federation \\ ${ }^{3}$ St. Petersburg State University, \\ 7-9, Universitetskaya nab., St. Petersburg, 199034, Russian Federation
}

For citation: Zadvorev S.F., Dorofeikova M.V., Petrova N.N., Yakovlev A. A. New possibilities of screening for mental disorders in cardiology practice. Vestnik of Saint Petersburg University. Medicine, 2021, vol. 16, issue 3, pp. 171-179. https://doi.org/10.21638/spbu11.2021.304

\begin{abstract}
Aim of the study: validation of novel algorithm for screening of mental comorbidity in general medical practice. Based on retrospectively formed registry of patients, we assessed an effectiveness of the previously proposed Psycho-cardiac comorbidity Index. An external validation was provided, with subgroup analysis on cohort of patients who presented with suspected "Non-ST-elevation acute coronary syndrome" $(\mathrm{N}=577)$, with assessment of psychopharmacotherapy prescription rate and prevalence of anxiety and depression. Another validation was carried out via comparison with patients with verified mental disorders $(\mathrm{N}=235)$. A positive association was found between magnitude of Psycho-cardiac comorbidity index and Hospital anxiety and depression subscales $(r=0.26, p<0.001$ for anxiety subscale, $r=0.17$, $\mathrm{p}=0.026$ for depression subscale), over-diagnosis of acute coronary syndrome at pre-hospital stage $(\mathrm{r}=-0.27, \mathrm{p}<0.0001)$, as well as with neurotic, affective and somatoform mental disorders (average Index 8.59 vs. 7.52 points, $\mathrm{U}=6040.5, \mathrm{p}=0.041$ ). The found pattern may be useful for clinicians for screening for patients who require a multidisciplinary approach to diagnosis and treatment.
\end{abstract}

Keywords: psychocardiology, acute coronary syndrome, screening of mental disorders, psychosomatics, anxiety, comorbidity.

\section{Introduction}

The mental disorders are highly prevalent in cardiology patients, with predominance of somatoform disorders and hypochondriasis (cumulatively over $30 \%$ patients), as well as affective and anxiety disorders $[1 ; 2]$. The current evidence exists that almost two-thirds hospitalized patients with acute myocardium infarction (MI) demonstrate depressive symptoms, with $15 \%$ prevalence of depressive episodes in patients with cardiovascular diseases (CVD), which is $2-3$-fold higher compared to general population. Patients with heart failure (HF) demonstrate even hither burden of depression, reaching up to $20 \%$, depending on HF functional class. 15-20\% patients experience depressive episode after coronary artery bypass grafting [3]. Anxiety disorders are found in 7-20\% patients with chronic coronary artery disease (CAD) $[4 ; 5]$, and phobic symptoms are 10 times more prevalent compared to general population [6]. Both anxiety and depression are associated

(C) St. Petersburg State University, 2021 
with risk of severe complications and death in patients with acute coronary syndromes (ACS) [7]. When diagnosed in time, mental disorders can be treated more effectively in cardiology patients, to increase their longevity and quality of life [8-10]. It was demonstrated that psychotherapy, mostly cognitive behavioral therapy, demonstrates mild to moderate 3-month improvement of symptoms in patients with non-specific chest pain without $\mathrm{CAD}$ [11]. In patients with verified CAD, the same intervention leads only to decrease in anxiety and depression [12]. Psychosocial assistance to stable CAD patients leads to improved quality of life, decrease in anxious and depressive symptoms and cardiovascular mortality.

Psychopharmacotherapy in practice of cardiologist was demonstrated to be efficient for correction of anxiety and depression in patients with MI [13] and with personal history of MI and pre-existed depressive symptoms [6]. Nonetheless, the prescription rate for psychopharmacotherapy is limited by concerns of drug-drug interactions [14].

Previously, we have proposed the Psycho-cardiac comorbidity index (PCI). An analysis showed that labile blood pressure, early manifestation of arrhythmias, female gender and multiple comorbidities are significant predictors for prescription of psychopharmacotherapy [15].

\section{Aims of the study}

Validation of a novel algorithm for screening of mental disorders in general medical patients by application of Psycho-cardiac comorbidity index on subpopulation of cardiology in-hospital patients; additional validation cohort of patients with verified mental disorders. Also, we investigated the potential additional role of an index in diagnostic protocol for patients presenting with suspected non-ST-elevation ACS (NSTE-ACS).

\section{Methods}

We carried out the retrospective observational two-center analysis of 956 medical records, forming 2 cohorts. For every patient, the PCI was calculated based on multiple linear regression, with the endpoint defined as prescription of psychopharmacotherapy for post-hospital stage. The formula of PCI was

$$
\mathrm{PCI}=8 \cdot \mathrm{L}+\mathrm{C}+3 \cdot \mathrm{F}+3(6) \cdot \mathrm{A},
$$

where PCI - Psycho-cardiac comorbidity Index; L - labile or paroxysmal arterial hypertension, defined as rapid increase of blood pressure over once a week; $\mathrm{C}-$ comorbidity count; $\mathrm{F}$ - female gender; $\mathrm{A}$ - arrhythmias or palpitations with onset at the age under 55 (3 points) or under 50 (6 points) [15].

The PCI validation cohort included 721 patients hospitalized into cardiology department during September 2016 to November 2019 (56.7\% females), the recruitment was continuous. Of them, 577 presented with suspected NSTE-ACS. The baseline demographic and medical characteristics are presented at table 1 for validation cohort and at table 2 for NSTE-ACS subgroups.

The additional cohort contained 235 continuously recruited patients who underwent in-hospital treatment due to previously verified mental disorder without urgent indications for hospitalization ( $74.7 \%$ females, mean age $66.0 \pm 12.5$ years). 
Table 1. Baseline characteristics of validation and additional group

\begin{tabular}{|l|l|l|l|}
\hline \multicolumn{1}{|c|}{ Parameter } & \multicolumn{1}{|c|}{$\begin{array}{c}\text { Validation } \\
\text { group }\end{array}$} & $\begin{array}{c}\text { NSTE-ACS } \\
\text { group }\end{array}$ & \multicolumn{1}{|c|}{$\begin{array}{c}\text { Additional } \\
\text { group }\end{array}$} \\
\hline Patients count & 721 & 577 & 235 \\
\hline Females, \% & 57.0 & 54.4 & 74.7 \\
\hline Mean age, years, $\mathrm{M} \pm \mathrm{m}$ & $68.0 \pm 12.6$ & $67.5 \pm 12.4$ & $66.0 \pm 12.5$ \\
\hline Labile blood pressure, \% & 24 & 26 & 25.0 \\
\hline Early onset of palpitations or paroxysmal arrhythmias, \% & 8.5 & 7.3 & 5.5 \\
\hline Mean comorbidities count, M $\pm \mathrm{m}$ & $3.60 \pm 1.79$ & $3.51 \pm 1.86$ & $3.62 \pm 2.09$ \\
\hline Mean PCI, M $\pm \mathrm{m}$ & $7.55 \pm 4.56$ & $7.49 \pm 4.74$ & $7.97 \pm 4.53$ \\
\hline
\end{tabular}

Table 2. Baseline characteristics of NSTE-ACS subgroups

\begin{tabular}{|c|c|c|c|c|c|}
\hline \multirow{2}{*}{ Parameter } & \multicolumn{3}{|c|}{ NSTE-ACS subgroup } & \multicolumn{2}{|c|}{$\begin{array}{c}\text { Significance for differences } \\
\text { between subgroups }\end{array}$} \\
\hline & Non-CAD & Stable CAD & ACS & $\mathrm{X}^{2}, \mathrm{P}$ & F, P \\
\hline Patients count & 302 & 76 & 219 & & \\
\hline Females, $\%$ & 59.8 & 64.3 & 44.2 & $21.25,<0.0001$ & \\
\hline Mean age, years, $M \pm m$ & $67.0 \pm 12.9$ & $71.0 \pm 11.0$ & $67.3 \pm 11.9$ & $7.54,0.0006$ & \\
\hline Labile blood pressure, $\%$ & 35 & 31 & 11 & $37.77,<0.0001$ & \\
\hline $\begin{array}{l}\text { Early onset of palpitations or } \\
\text { paroxysmal arrhythmias, \% }\end{array}$ & 10.9 & 7.1 & 3.4 & $12.96,0.0004$ & \\
\hline $\begin{array}{l}\text { Mean comorbidities count, } \\
M \pm \mathrm{m}\end{array}$ & $3.48 \pm 1.79$ & $4.61 \pm 2.41$ & $3.36 \pm 1.80$ & & $\begin{array}{l}3.75 \\
0.0240\end{array}$ \\
\hline Mean PCI, $\mathrm{M} \pm \mathrm{m}$ & $9.33 \pm 4.97$ & $8.64 \pm 4.85$ & $5.01 \pm 3.05$ & & $\begin{array}{l}45.88 \\
<0.0001\end{array}$ \\
\hline
\end{tabular}
groups.

Note: Statistical significance (Chi-square, F, P) is given for differences between all 3 NSTE-ACS sub-

The latter cohort was divided into 2 subgroups (see table 3 ), defined on typical or non-typical somatic or medically unexplained physical symptoms [16]:

1. ICD-10 F3x (affective disorders), F4x (neurotic, stress-related and somatoform disorders) and F6x (disorders of adult personality and behaviour) subgroup, $\mathrm{n}=107$ (82, 22 and 3 patients, respectively).

2. ICD-10 F0x (organic, including symptomatic, mental disorders) and F2x (schizophrenia, schizotypal and delusional disorders) subgroup, $\mathrm{n}=128$ (112 and 16 patients, respectively).

As the design of the study was retrospective observational, no informed consent needed for inclusion. 
Exclusion criteria: in-hospital death, lack of demographic or medical data on personal history and prescribed medications.

The following data were collected and subsequently analyzed:

1. The fact of prescription of psychopharmacotherapy for post-hospital medication.

2. Demographic factors (gender, age).

3. Personal history of CVD and cardiac interventions or surgery.

4. Comorbidities, including potentially psychosomatic diseases.

5. Assessment of anxiety and depression with Hospital Anxiety and depression scale (HADS) [17].

6. Final diagnoses for validation cohort, including comorbidities and conditions associated with high prevalence of affective, cognitive disorders and autonomous dysfunction.

7. For additional cohort, the major symptoms at admission and the final diagnosis were also collected (anxiety, anhedonia, hypochondriasis, delusions, depersonalization, insomnia, sensory hallucinations, cognitive decline).

Statistics were performed with SPSS 23.0 (IBM Inc., USA). We used the descriptive statistics, Kolmogorov - Smirnov test for normal distribution, parametric and non-parametric analyses, i. e. Spearman and Pearson correlations, Mann - Whitney U-criterion. Statistical significance was determined as $\mathrm{P}<0.05$.

\section{Results}

\section{Diagnosis of mental comorbidities in cardiology patients}

Of 721 patients from the validation cohort, 80 were diagnosed with various mental disorders before admission. 34 patients (4.7\%) were assessed by neurologist, 2 and 1 were consulted by psychiatrist and psychotherapist, respectively. 70 (9.7\%) patients received recommendations do be furtherly observed by neurologist, 12 and 21 by psychiatrist and psychotherapist, respectively. Table 3 represents the symptoms and syndromes found in these patients. Fatigue and cognitive deficiency were the most common findings. 11 participants had medically unexplained chronic pains.

\section{Prognostic meaning of PCI in patients with suspected NSTE-ACS}

An additional retrospective analysis was provided for 577 participants who were hospitalized due to suspected NSTE-ACS. During in-hospital assessment, in 302 cases complaints were found to be non-cardiac, 76 were attributed to stable CAD, and in 219 cases initial diagnosis was confirmed (see table 2). Patients from the last subgroup were less likely to be women, to have labile arterial hypertension and early onset of cardiac arrhythmias.

An association between probability of confirmed NSTE-ACS and magnitude of psycho-cardiac comorbidity index (see Figure). The percentage on ruled-out ACS positively correlated with was higher with psycho-cardiac comorbidity index $\left(r=-0.27, \mathrm{p} \sim 10^{-10}\right)$. 
Table 3. Prevalence of mental conditions and symptoms in validation group and additional group

\begin{tabular}{|c|c|c|c|}
\hline Conditions and symptoms & $\begin{array}{c}\text { Prevalence } \\
\quad(\mathrm{N}, \%)\end{array}$ & Conditions and symptoms & $\begin{array}{c}\text { Prevalence } \\
\quad(\mathrm{N}, \%)\end{array}$ \\
\hline \multicolumn{2}{|l|}{ Validation cohort } & \multicolumn{2}{|c|}{ Additional cohort } \\
\hline Fatigue & $31(4.3)$ & Anxiety & $196(82)$ \\
\hline Dementia / cognitive deficit & $25(3.5)$ & Hypochondriasis & $66(27)$ \\
\hline Somatoform autonomous dysfunction & $18(2.5)$ & Mood instability & $49(21)$ \\
\hline Anxious disorders & $9(1.2)$ & Senestopathy & $43(19)$ \\
\hline Hypochondriasis & $8(1.1)$ & Depersonalization & $34(14)$ \\
\hline Epilepsy & $5(0.7)$ & Insomnia & $158(65)$ \\
\hline Depression & $4(0.6)$ & Anhedonia & $99(41)$ \\
\hline \multirow[t]{3}{*}{ Other (e.g. delirium, acute psychoses) } & $12(1.7)$ & Cognitive deficit & $94(38)$ \\
\hline & & Hallucinations & $32(13)$ \\
\hline & & Delusions & $54(22)$ \\
\hline
\end{tabular}

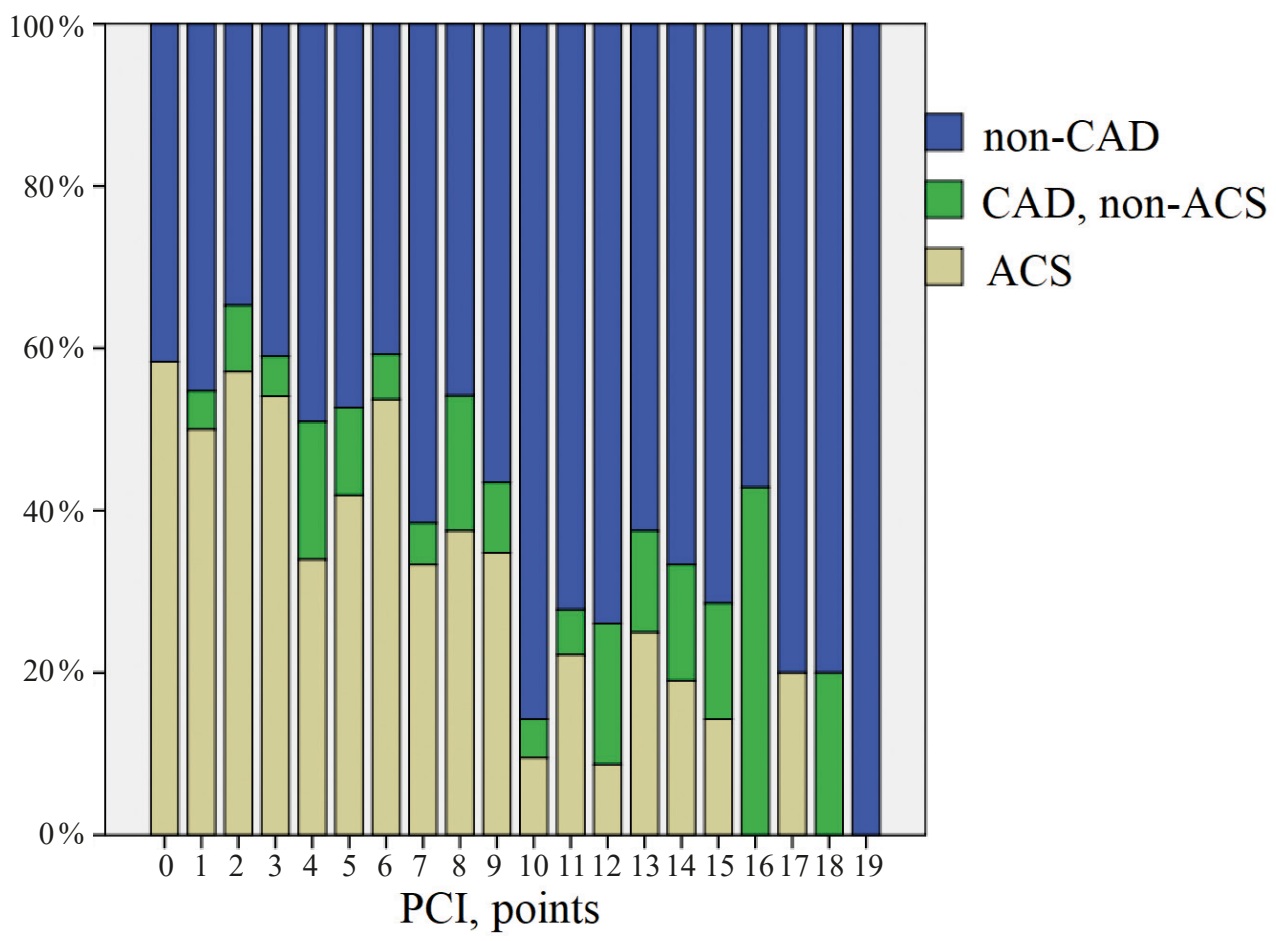

Figure. Percentage of confirmed and excluded NSTE-ACS in patients with different PCI scores 


\section{Application of psycho-cardiac comorbidity index to the people with verified mental disorders}

The PCI was applied to additional cohort of patients with verified mental disorders. Results demonstrated parallelism between PCI score and separate domains of mental diseases. The spectrum of mental conditions is presented at Table 3.

The mean PCI score on F0x-F2x subgroup was lower compared to F3x-F4x-F6x subgroup (mean score $7.52 \pm 4.38$ vs. $8.59 \pm 4.62$ points, respectively, $\mathrm{U}=6040.5, \mathrm{p}=0.041$ ). When assessed the association of symptoms with PCI, a negative one was found between delusions and proposed index ( $8.47 \pm 4.45$ vs. $6.59 \pm 4.48$ points, $\mathrm{U}=3530.5, \mathrm{p}=0.007)$. There was a tendency to lower rate of prescription of vasoactive substances in patients with higher PCI ( $6.55 \pm 4.14$ vs. $8.26 \pm 4.56$ points, $\mathrm{p}=0.057)$. Another symptoms and medications demonstrated no association with PCI index.

\section{Psycho-cardiac comorbidity index and \\ Hospital anxiety and depression scale}

Of the validation cohort, 231 patients were screened for anxiety and depression with hospital anxiety and depression scale (HADS) (60\% females, mean age $67.6 \pm 11.5$ years). In 57 cases $(24.7 \%)$ the results were incomplete; 168 anxiety subscales and 172 depression subscales were found eligible for further analysis. Of them, 87 scales were collected from patients who presented with suspected NSTE-ACS.

Mean anxiety subscale was $7.58 \pm 3.80$ points $(6.18 \pm 3.54$ for men and $8.54 \pm 3.69$ for women, $\mathrm{F}(1)=22.25, \mathrm{p}=0.0001)$; the mean depression subscale was $6.89 \pm 3.69$ points (5.75 \pm 3.81 for men, $7.66 \pm 3.43$ for women, $F(1)=13.49, p=0.0002)$. Distribution or results by clinical groups is presented at Table 4 .

Higher PCI positively correlated with higher anxiety $(\mathrm{r}=0.26, \mathrm{p}<0.001)$ and depression HADS subscales $(\mathrm{r}=0.17, \mathrm{p}=0.026)$. Regression coefficient between PCI and anxiety subscale was $0.256 \pm 0.082$ (i.e. PCI increase at 10 points corresponds to mean HADS-A increase at 2.56 points). The regression coefficient for depression subscale was $0.173 \pm 0.088$.

Table 4. Prevalence of anxiety and depression in validation group

\begin{tabular}{|l|c|c|c|}
\hline \multicolumn{1}{|c|}{ Clinical Group } & Men & Women & $\begin{array}{c}\text { General } \\
\text { subgroup }\end{array}$ \\
\hline No anxiety & 67.6 & 43.5 & 53.3 \\
\hline Subclinical anxiety & 19.7 & 28.7 & 25 \\
\hline Symptomatic anxiety & 12.7 & 27.8 & 21.7 \\
\hline No depression & 69.0 & 49.6 & 56.7 \\
\hline Subclinical depression & 24.3 & 33.0 & 28.9 \\
\hline Symptomatic depression & 6.7 & 17.4 & 13.4 \\
\hline
\end{tabular}




\section{Discussion}

This study was carried out to assess the prognostic meaning of previously proposed psycho-cardiac comorbidity index for ruling out NSTE-ACS and for screening of mental diseases in general population (firstly, screening of anxiety and depression).

Chest pain is a common symptom of somatoform disorder in general practice. American heart association recommended to screen the patients with CAD for depression in 2008 [10]. Palpitations and chest pain often have non-cardiac origin. Such symptoms may be caused by somatic conditions or medically unexplained. The last group of conditions is responsible for 7 to $17 \%$ of chest pain cases in primary care. It may be misinterpreted as ACS. Various mental conditions (i.e. affective, anxiety, somatoform) are found in over $50 \%$ of emergency cardiac care consumers, especially in cases when no "medically explained symptoms" were found [18]. Due to temporary challenges and impossibility to apply the response forms in long-term, screening for anxiety and depression is complicated [19], forcing to search alternative ways of screening for psycho-cardiac comorbidity. An algorithm proposed in this study is one of such ways.

The most common complaints attributed to mental conditions, according to our study, were fatigue and cognitive deficit. It is contrary to data from other registries showing higher prevalence of anxious and depressive disorders in cardiology patients.

For example, according to S. F. Mujtaba et al. (2020), patients with negative coronary angiography demonstrated $37 \%$ (for males) and $22 \%$ (for females) higher volume of anxiety compared to persons with objectified ACS [20]. According to the same source, the prevalence of anxiety and depression in cardiology population was $10 \%$ and $8 \%$, respectively [20].

Our study demonstrates gender-specific distribution of anxiety and depression HADS subscales, corresponding to most of the data on this subject.

In general, the data collected during this study, highlight the high significance of mental status in diagnostic algorithms and treatment of patients with cardiac urgent conditions and need for paying special attention to it [6].

The retrospective two-center design of this study is its limitation. Further validation of proposed index on other medical groups is needed (firstly, in pulmonology and gastroenterology departments, were burden of psychosomatic disorders is high).

As alexithymia is known to contribute to clinical presentation of psychosomatic disorders, this aspect should be also evaluated in context of screening for mental conditions in general practice. Another factor that should not be neglected is a variable nociceptive threshold in patients with labile blood pressure (which might be triggered by chronic pain). Further prospective randomized trials are needed to estimate contribution of these factors into course of cardiac diseases.

\section{Conclusions}

The proposed Psycho-cardiac comorbidity index is a valid additional diagnostic tool to rule-out the non-ST-elevation ACS, representing the anxious and depressive symptoms in cardiac in-hospital patients.

The found social, demographic and neurological profiles of high-PCI patients correspond to ones found in patients with verified affective, somatoform and psychogenic 
disorders. These patients need interdisciplinary approach and initiation of psychopharmacotherapy should be considered.

\section{References}

1. Smulevich A. B., Andryuschenko A. V., Beskova D. A. Clinical and epidemiological program SINTEZ: prevalence and structure on mental disorders in general medicine. Mental diseases in clinical practice, ed. by A. B. Smulevich. Moscow: Medpress-inform Publ., 2011, pp. 230-309. (In Russian)

2. Kotsyubinsky A.P., Petrova N.N. Somatoform, somatopsychiatric and psychosomatic disorders: a textbook. Saint Petersburg. St. Petersburg: St. Petersburg scientific research Institute named after V. M. Bekhterev Publ., 2015. 68 p. (In Russian)

3. Novak Sarotar B., Lainscak M. Psychocardiology in the elderly. Wien Klin Wochenschr, 2016, vol. 128, suppl. 7, pp. 474-479.

4. Bunevicius A., Staniute M., Brozaitiene J., Pop V. J., Neverauskas J., Bunevicius R. Screening for anxiety disorders in patients with coronary artery disease. Health and Quality of Life Outcomes, 2013, vol. 11, p.37.

5. Gorini A., Giuliani M., Raggio L., Barbieri S., Tremoli E. Depressive and anxiety symptoms screening in cardiac inpatients: a virtuous Italian approach to psychocardiology. Int. J. Environ. Res. Public Health, 2020, vol. 17, no. 14, p. 5007. https://doi.org/10.3390/ijerph17145007

6. Ladwig K.-H., Lederbogen F., Albus C. Position paper on the importance of psychosocial factors in cardiology: Update 2013. GMS German Medical Science, 2014, vol. 12, Doc09. https://doi. org/10.3205/000194

7. $\quad$ Li J., Ji F., Song J., Gao X., Jiang D., Chen G., Chen S., Lin X., Zhuo Ch. Anxiety and clinical outcomes of patients with acute coronary syndrome: a meta-analysis. BMJ Open, 2020, vol. 10, no. 7, p. e034135. https://doi.org/10.1136/bmjopen-2019-034135

8. Petrova N.N. Comorbid mental disorders as a factor of efficacy of treatment and rehabilitation for cardiologic patients. Bulletin of ESSC RAMS, 2016, vol.1, no.6, pp. 88-91. (In Russian)

9. Lichtman J.H., Bigger J.T.Jr., Blumenthal J.A., Frasure-Smith N., Kaufmann P.G., Lespérance F., Mark D. B., Sheps D.S., Taylor C. B., Froelicher E. S. Depression and coronary heart disease. Recommendations for screening, referral, and treatment. Circulation, 2008, vol. 118, pp. 1768-1775.

10. Rutledge T., Reis V. A., Linke S. E., Greenberg B. H., Mills P. J. Depression in heart failure a meta-analytic review of prevalence, intervention effects, and associations with clinical outcomes. J. Am. Coll. Cardiol., 2006, vol. 48, no. 8, pp. 1527-1537.

11. Kisely S. R., Campbell L. A., Yelland M. J., Paydar A. Psychological interventions for symptomatic management of non-specific chest pain in patients with normal coronary anatomy. Cochrane Database of Systematic Reviews, 2015, vol. 6, art. no. CD004101.

12. Richards S.H., Anderson L., Jenkinson C.E., Whalley B., Rees K., Davies P., Bennett P., Liu Z., West R., Thompson D. R., Taylor R. S. Psychological interventions for coronary heart disease. Cochrane Database Syst. Rev., 2017, vol. 4, no. 4, art. no. CD002902. https://doi.org/10.1002/14651858.CD002902. pub4

13. Petrova N.N., Kutuzova A.E. Interdisciplinary approach to management of patients with life-threatening comatic condition. Obozreniye psikhiatrii I meditsinskoi psikhologii im. V.M. Bekhtereva, 2014, vol. 1, pp. 97-104. (In Russian)

14. Piña I.L., Di Palo K.E., Ventura H.O. Psychopharmacology and cardiovascular disease. J. Am. Coll. Cardiol., 2018, vol. 71, no. 20, pp. 2346-2359. https://doi.org/10.1016/j.jacc.2018.03.458

15. Dorofeikova M. V., Zadvorev S.F., Petrova N.N., Yakovlev A.A. On the issue of allocation of a risk group for the presence of mental disorders in the practice of cardiology department. Acta biomedica scientifica, 2017, vol. 2, no. 5, pp. 114-121. (In Russian)

16. Mann S. J. Labile and paroxysmal hypertension: common clinical dilemmas in need of treatment studies. Curr. Cardiol. Rep., 2015, vol. 17, pp. 99-104.

17. Zigmond A.S., Snaith R. P. The hospital anxiety and depression scale. Acta Psychiatrica Scandinavica, 1983, vol. 67, no. 6, pp. 361-370.

18. Prokopenko S.V., Petrova M.M., Koryagina T.D., Shanina Y.G. Discirculatory encephalopathy in practice of out-patient doctor. Poliklinika, 2015, vol. 3, pp. 48-52. (In Russian)

19. Berge T., Bull-Hansen B., Solberg E.E., Heyerdahl E. R., Jørgensen K. N., Vinge L.E., Aaronaes M., Oie E., Hyldmo I. Screening for symptoms of depression and anxiety in a cardiology department. Tidsskr Nor Laegeforen, 2019, vol. 139, no. 14. https://doi.org/10.4045/tidsskr.18.0570. PMID: 31592606. 
20. Mujtaba S. F., Sial J. A., Karim M. Depression and Anxiety in patients undergoing percutaneous coronary intervention for acute coronary syndrome. Pak. J. Med. Sci., 2020, vol. 36, no. 5, pp. 1100-1105. https://doi.org/10.12669/pjms.36.5.1749

Received: May 17, 2021 Accepted: September 17, 2021

Authors' information:

Sergei F.Zadvorev - MD; zadvoryevsf@yandex.ru

Natalia N.Petrova - MD, PhD, Professor; petrova_nn@mail.ru

Mariia V. Dorofeikova - MD, PhD, Researcher; mvdorofeykova@mail.ru

Artyom A. Yakovlev - MD, PhD; yakotema@gmail.com 